\title{
Serum Levels of Irisin and Vaspin in Diabetic Retinopathy Patients and Their Relation to Patient's Obesity
}

\author{
Ali Muhye Aldeen Rasheed ${ }^{1}$, Muayad Khalaf Ibrahim ${ }^{2}$, Abdulmalek Shallal Ajmi \\ ${ }^{1}$ M. B. Ch. B., FICMS, Lecturer in Ophthalmogy, ${ }^{2}$ M. B. Ch. B., Lecturer in Internal Medicine, \\ ${ }^{3}$ M. B. Ch. B., FICMS, Lecturer in Ophthalmogy, College of Medicine, Tikrit University, Iraq
}

\begin{abstract}
The s study was carried out in Kirkuk city, from $20^{\text {th }}$ January to September to November 2019 included 40 Diabetic patients with retinopathy and 40 healthy persons within the range of age: 45-75 years of old. The information about patients in this study was retrieved from patient's itself. The diabetic patients with retinopathy were diagnosed by analysis RBS and HbAlc and fundoscopical examination by the ophthalmologist. The criteria of exclusion include non-diabetic and malignant disease. The results of the patients groups were compared with healthy individuals nearly comparable age and BMI. Four ml of blood were collected from patients and for determination of irisin, vaspin and HbAlc. The study showed that the mean serum level of irisin was significantly elevated in DR patients compared to control group (27.57 \pm 4.22 and $17.57 \pm 5.9 \mathrm{pg} / \mathrm{ml}$ ) respectively at a $\mathrm{P}$ value $<0.01$. This study showed that the mean serum level vaspin was higher in DR patients especially in persons with high BMI and decreased in lower BMI persons (75.1, 59.3 and $48.3 \mathrm{ng} / \mathrm{ml})$ respectively but still higher than healthy ones $(\mathrm{P}<0.01)$, as compared with the control group $(32.17 \mathrm{ng} / \mathrm{ml})$. The study showed that, HbA1c was elevated significantly $(\mathrm{P}<0.01)$ in diabetic retinopathy patients $(10.17 \%)$ compared with healthy control $(5.17 \%)$,. The study concluded that, vaspin and irisin levels were highly elevate din diabetic patients with retinopathy.
\end{abstract}

Keywords: Malondialdehyde; Diabetic retinopathy; Oxidative stress; HbAlc.

\section{Introduction}

Diabetes mellitus (DM) is expected to affect around 550 million people all over the world according to global estimates of the prevalence of diabetes ${ }^{(1)}$. $\mathrm{DM}$ is characterized by constant hyperglycemia that damages various organs and manifests in macro vascular complications like premature atherosclerosis resulting in strokes, peripheral vascular disease, and myocardial infarctions and micro vascular complications such as nephropathy, neuropathy, and retinopathy ${ }^{(2)}$. Diabetic retinopathy (DR) is the number one cause of blindness in people between 27 and 75 years of age. Prevalence ofDR is around $25 \%$ and $90 \%$ at 5 and 20 years, respectively, from diagnosis; it is calculated that 191 million people will be diagnosed with this micro-vascular complication by the year $2030^{(3)}$. Through the last three decades, extensive scientific reports have shown ROS to play an important role in DM complications such as diabetic neuropathy, nephropathy, and retinopathy due to alterations on the biomechanisms involved in the instauration and progression of micro-vascular complications ${ }^{(4)}$. These three micro-vascular complications share high glucose levels as a starting point; such condition is necessary, but may not be enough to initiate the damage present in the peripheral nervous system (neuropathy), kidneys (nephropathy), and retinas (retinopathy) of diabetic patients $^{(5,6)}$. Hyperglycemic states favor the activation of alternative pathways leading to reactive oxygen species (ROS) formation and augmented concentrations locally and in the rest of the body even at the point of surpassing the antioxidant capacity, a state known as oxidative stress affecting retinal integrity ${ }^{(7,8)}$. The study aim of this work was to evaluate the level of Malondialdehyde (MDA) in diabetic patients with and without retinopathy and healthy controls.

\section{Patients and Method}

The study was carried out in Kirkuk city, from $20^{\text {th }}$ January to September to November 2019 included 
40 Diabetic patients with retinopathy and 40 healthy persons within the range of age: $45-75$ years of old. The information about patients in this study was retrieved from patient's itself. The diabetic patients with retinopathy were diagnosed by analysis RBS and HbAlc and fundoscopical examination by the ophthalmologist. The criteria of exclusion include non-diabetic and malignant disease. The results of the patients groups were compared with healthy individuals nearly comparable age and
BMI.Four $\mathrm{ml}$ of blood were collected from patients and controls in plain tubes without any anticoagulant at room temperature for 10-15 minutes and allowed to clot. The tube then were centrifuged $(3000 \mathrm{rpm})$ for $15 \mathrm{~min}$. The clear serum was pipetted into clear dry Eppendorf's and stored at $\left(-20^{\circ} \mathrm{C}\right)$ until used for the various investigations. The levels of malondialdehyde, HbA1c were measured by using immunofluorescence technique.

\section{Results}

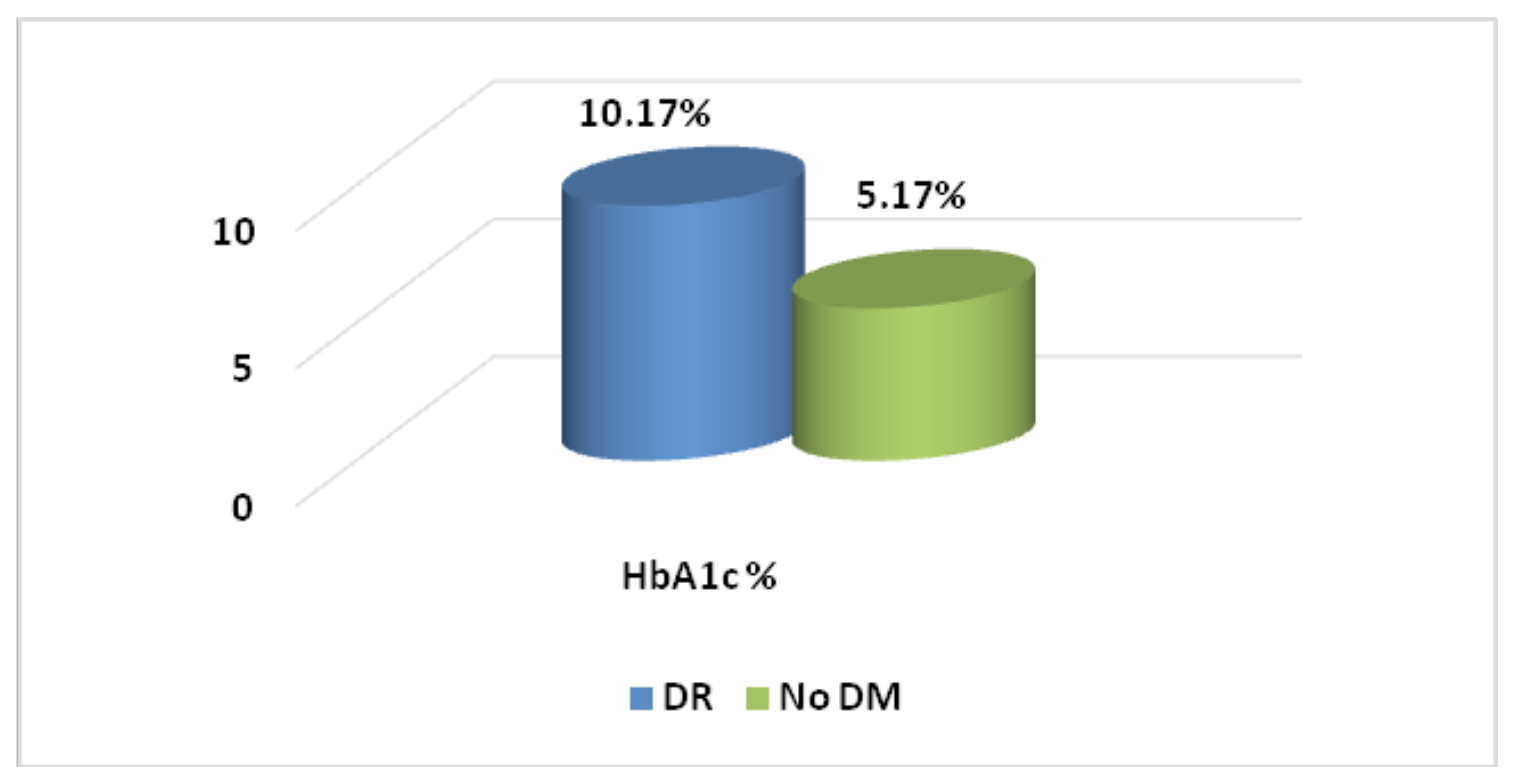

Figure 1:Means of HbA1c levels in the studied groups

\section{In the following Table 1, general characteristics of DR patients:}

Table 1: Distribution of the general characteristics Diabetes patients

\begin{tabular}{|l|l|c|}
\hline \multicolumn{2}{|l|}{ Parameters } & $\boldsymbol{n ( \% )}$ \\
\hline \multirow{4}{*}{ BMI $\left(\mathrm{kg} / \mathrm{m}^{2}\right)$} & Non-Obese $(18.524 .9)$ & 30 \\
\cline { 2 - 3 } & Overweight $(25-29.9)$ & 30 \\
\cline { 2 - 3 } & Obese $\geq 30$ & 40 \\
\hline \multirow{5}{*}{ Age (years) } & $17-26$ & 12 \\
\cline { 2 - 3 } & $27-36$ & 14 \\
\cline { 2 - 3 } & $37-46$ & 24 \\
\cline { 2 - 3 } & $47-56$ & 25 \\
\cline { 2 - 3 } & $57-66$ & 17 \\
\cline { 2 - 3 } & $67-76$ & 8 \\
\cline { 2 - 3 } & Mean: $45.01 \pm 4.5$ & \\
\hline
\end{tabular}

\begin{tabular}{|l|l|c|}
\hline \multicolumn{2}{|l|}{ Parameters } & $\boldsymbol{n ( \% )}$ \\
\hline \multirow{2}{*}{ Sex } & Males & 36 \\
\cline { 2 - 3 } & Females & 64 \\
\hline
\end{tabular}

As shown in Table 2, the mean serum level of irisin was significantly elevated in DR patients compared to control group $(27.57 \pm 4.22$ and $17.57 \pm 5.9 \mathrm{pg} / \mathrm{ml})$ respectively at a $\mathrm{P}$ value $<0.01$.

Table 2: The mean and standard deviation (SD) of irisin level in studied groups

\begin{tabular}{|l|c|c|}
\hline Irisin level (pg/ml) & DR patients & Control group \\
\hline No. & 40 & 40 \\
\hline Mean & 27.57 & 23.98 \\
\hline SD. & 4.22 & 5.9 \\
\hline
\end{tabular}

$\mathrm{P}<0.01$ 
This study showed that the mean serum level vaspin was higher in DR patients especially in persons with high BMI and decreased in lower BMI persons (75.1, 59.3 and $48.3 \mathrm{ng} / \mathrm{ml}$ ) respectively but still higher than healthy ones $(\mathrm{P}<0.01)$, as compared with the control group $(32.17 \mathrm{ng} / \mathrm{ml})$. This result was highly significant at a $P$ value of 0.001 , Table 2 .

Table 3: Relation of vaspin with obesity of DM patients

\begin{tabular}{|l|c|c|c|c|}
\hline \multirow{2}{*}{$\begin{array}{l}\text { Vaspin level } \\
\text { (ng/ml) }\end{array}$} & \multicolumn{3}{|c|}{ DR patients } & \multirow{2}{*}{$\begin{array}{c}\text { Control } \\
\text { group }\end{array}$} \\
\cline { 2 - 4 } & Obese & Overweight & Normal & 30 \\
\hline No. & 10 & 20 & 10 & 32.17 \\
\hline Mean & 75.1 & 59.3 & 48.3 & 4.28 \\
\hline SD. & 6.8 & 5.9 & 5.2 & \\
\hline
\end{tabular}

$\mathrm{P}<0.01$

The study showed that, HbAlc was elevated significantly $(\mathrm{P}<0.01)$ in diabetic retinopathy patients $(10.17 \%)$ compared with healthy control (5.17\%), Figure 1.

\section{Discussion}

In several studies, women had significantly higher rate of DR than men, as it seems that females may take care about their general health more than males, which is similar to a study in Sweden where women had a higher rate than men ${ }^{(1-3)}$. Esteghamati et al ${ }^{(10)}$ also established that, there was significant relation of irisin and vasoin with occurrence and developmentof diabetic retinopathy. While Choiet al ${ }^{(11)}$ in recent study reported that the rate of diabetic retinopathy was significantly associated with elevation of vaspin in obese DR patients. In agreement with the current results, Jeonget $a l^{(12)}$ indicated a highly significantly increased irisin levels, in cases with respect to controls, point towards a role of free radicals in causation of diabetic complications like retinopathy. In addition, Rickhamet $a l^{(13)}$ showed that, serum irisin has been found to be significantly associated with the severity of DR in patients with type 2 insulin-dependent DM. Taal et $a l^{(14)}$ reported that increased vaspin is associated with oxidative stress and poor antioxidant defense, which promotes the progression of DR to its proliferative form. Some other studies speculate that retinal microvascular complications are closely related to the severity of oxidative stress, as expressed as increased level of MDA among DR patients ${ }^{(7,8)}$. Indeed, the exact mechanism by which the oxidative stress contributes to diabetic complications remains unclear, but all biochemical alterations due to DM lead to anatomical and functional impairment in the retinal microvascular network, such as changes in blood flow in the retina, disruption of the blood-retina-barrier and consequently capillary occlusion and ischemia ${ }^{(15)}$. Moreover, El-Mesallamyet $a l^{(16)}$ showed that, serum vaspin was significantly higher in DR patients and the lowest mean was in the control group. Al- El-Lebedy et al ${ }^{(17)}$ in thier study showed that, $\mathrm{HbA} 1 \mathrm{C}$ was elevated significantly in DR group followed by DM patients and indicating that poor glycemic control is a strong predictor for the development of DR. Our findings were also consistent with that stated by other studies in the world ${ }^{(17,18)}$. The elevated levels of HbAlc in DR patients may be due to their induction of retinal inflammation and vascular leakage due to their effect on blood vessels which may lead to retinal cell death ${ }^{(7)}$. The positive association between DR and duration of diabetes is noted in the literature. The retinopathy rate in Southern India was $7 \%$ in individuals with short duration of diabetes (less than 10 years), 26\% in those with 10 14 years duration and $63 \%$ in those with 15 years and more duration of diabetes ${ }^{(6)}$. Our findings were also in agreement with the well established statement of several studies denoted that the severity of retinopathy is strongly associated with the duration of diabetes ${ }^{(19,20)}$. Navneetet $a l^{(27)}$ showed level OF Vaspin increased as the grade of obesity increased performed a similar study and reported that the concentration of MDA increased with increasing BMI, which was found to be statistically in overweight subjects.

\section{Conclusions}

The study concluded that, vaspin and irisin levels were highly elevate din diabetic patients with retinopathy.

Financial Disclosure: There is no financial disclosure.

Conflict of Interest: None to declare.

Ethical Clearance: All experimental protocols were approved under the College of Medicine and all experiments were carried out in accordance with approved guidelines.

\section{References}

1. Liebl A. Challenges in optimal metabolic control of diabetes. Diabetes Metab Res Rev 2002; 18: S36-S41.

2. Chang YC, Wu WC. Dyslipidemia and diabetic 
retinopathy. Rev Diabet Stud 2013; 10: 121-132.

3. Simo R, Hernandez C. Prevention and treatment of diabetic retinopathy: evidence from large, randomized trials. The emerging role of fenofibrate. Rev Recent Clin Trials 2012; 7: 71-80.

4. Murri M, Insenser M, Luque M, Tinahones FJ, Escobar-Morreale HF. Proteomic analysis of adipose tissue: informing diabetes research. Expert Rev Proteomics 2014; 11: 491-502.

5. Al-Azzam SI, Alzoubi KH, Abeeleh JA, Mhaidat NM, Abu-Abeeleh M. Effect of statin therapy on vaspin levels in type 2 diabetic patients. ClinPharmacol 2013; 5: 33-38.

6. Baltadjiev AG, Vladeva SV. Correlations between human somatotype components and some anthropometric parameters in male patients with type 2 diabetesmellitus. Folia Med (Plovdiv) 2014; 56: $175-181$.

7. Derosa G, Ragonesi PD, Carbone A, Fogari E, D'Angelo A, Cicero AF, Maffioli P. Evaluation of the positive effects on insulin-resistance and $\beta$-cell measurements of vildagliptin in addition to metformin in type 2 diabetic patients. Pharmacol Res 2013; 73: 20-26.

8. Hida K, Wada J, Eguchi J, Zhang H, Baba M, Seida A, Hashimoto I, Okada T, Yasuhara A, Nakatsuka A, Shikata K, Hourai S, Futami J, Watanabe E, Matsuki Y, Hiramatsu R, Akagi S, Makino H, Kanwar YS. Visceral adipose tissue-derived serine protease inhibitor: a unique insulin-sensitizing adipocytokine in obesity. ProcNatlAcadSci USA 2005; 102: 10610-10615.

9. Cui Y, Jiao Y, Chen HJ, Ding J, Luo B, Peng CY, $\mathrm{Ju}$ SH, Teng GJ. Aberrant functional connectivity of default-mode network in type 2 diabetes patients. EurRadiol 2015; 25: 3238-3246.

10. Esteghamati A, Mousavizadeh $\mathrm{M}$, Noshad $\mathrm{S}$, Zandieh A, Zarei H, Nakhjavani M. Genderdependent effects of metformin on vaspin and adiponectin in type 2 diabetes patients: a randomized clinical trial. HormMetab Res 2013; 45: 319-325.

11. Choi SH, Kwak SH, Lee Y, Moon MK, Lim S, Park YJ, Jang HC, Kim MS. Plasma vaspin concentrations are elevated in metabolic syndrome in men and are correlated with coronary atherosclerosis in women. ClinEndocrinol (Oxf) 2011; 75: 628-635.

12. Jeong SU, Lee SK. Obesity and gallbladder diseases. Korean J Gastroenterol 2012; 59: 27-34.

13. Rickham PP. Human experimentation. Code of ethics of the world medical association. Br Med J 1964; 2: 177.

14. MW. Chronic kidney disease 10 years on: what have we learned? CurrOpinNephrolHypertens 2012; 21: 607-611.

15. Silverman GA, Bird PI, Carrell RW, Church FC, Coughlin PB, Gettins PG, Irving JA, Lomas DA, Luke CJ, Moyer RW, Pemberton PA, RemoldO'Donnell E, Salvesen GS, Travis J, Whisstock JC. The serpins are an expanding superfamily of structurally similar but functionally diverse proteins. Evolution, mechanism of inhibition, novel functions, and a revised nomenclature. J BiolChem 2001; 276: 33293-33296.

16. El-Mesallamy HO, Kassem DH, El-Demerdash E, Amin AI. Vaspin and visfatin/Nampt are interesting interrelated adipokines playing a role in the pathogenesis of type 2 diabetes mellitus. Metabolism 2011; 60: 63-70.

17. El-Lebedy DH, Ibrahim AA, Ashmawy IO. Novel adipokinesvaspin and irisin as risk biomarkers for cardiovascular diseases in type 2 diabetes mellitus. Diabetes \& Metabolic Syndrome: Clinical Research \& Reviews. 2018 Sep 1;12(5):643-8.

18. Buranapin S, Siangruangsang S, Chantapanich $\mathrm{V}$, Hengjeerajarus N. The comparative study of diabetic specific formula and standard formula on postprandial plasma glucose control in type $2 \mathrm{DM}$ patients. J Med Assoc Thai 2014; 97: 582-588.

19. Yang L, Chen SJ, Yuan GY, Wang D, Chen JJ. Changes and clinical significance of serum vaspin levels in patients with type 2 diabetes. Genet Mol Res 2015; 14: 11356-11361.

20. Akbarzadeh S, Nabipour I, Jafari SM, Movahed A, Motamed N, Assadi M, Hajian N. Serum visfatin and vaspin levels in normoglycemic first-degree relatives of Iranian patients with type 2 diabetes mellitus. Diabetes Res ClinPract 2012; 95: 132138. 